\section{Allergieprävention 1: Waldorfschule}

Bereits im Jahr 1999 hatte eine Untersuchung gezeigt, dass die Allergieprävalenz bei Kindern, die eine Waldorfschule besuchen, geringer ist als bei anderen Schülern (Lancet 1999; 353:1485-8). Konkrete protektive Faktoren zu identifizieren, war das Ziel der im Januar dieses Jahres erschienen Nachfolgestudie.

ie PARSIFAL-Arbeitsgruppe (Prevention of Allergy - Risk Factors for Sensitization Related to Farming and Anthroposophic Lifestyle) beschäftigt sich seit Jahren mit der Frage, warum Waldorfschulkinder seltener Allergien entwickeln. Für die aktuelle Untersuchung wurden die Eltern von 6.630 Kindern, davon 4.606 Waldorfschulkinder, im Alter von fünf bis 15 Jahren aus fünf europäischen Ländern mit Hilfe des standardisierten Fragebogens der ISAAC (International Study of Asthma and Allergies in Childhood) befragt. Bei $28 \%$ der Kinder bestimmten die Wissenschaftler zusätzlich spezifische IgE-Antikörper im Blut.

Es zeigten sich deutliche Unterschiede zwischen anthroposophischen und anderen Familien hinsichtlich klassischer Allergierisikofaktoren: Eltern von Waldorfschulkindern rauchten weniger und waren häufiger Akademiker, litten aber auch öfter unter allergischen Er-

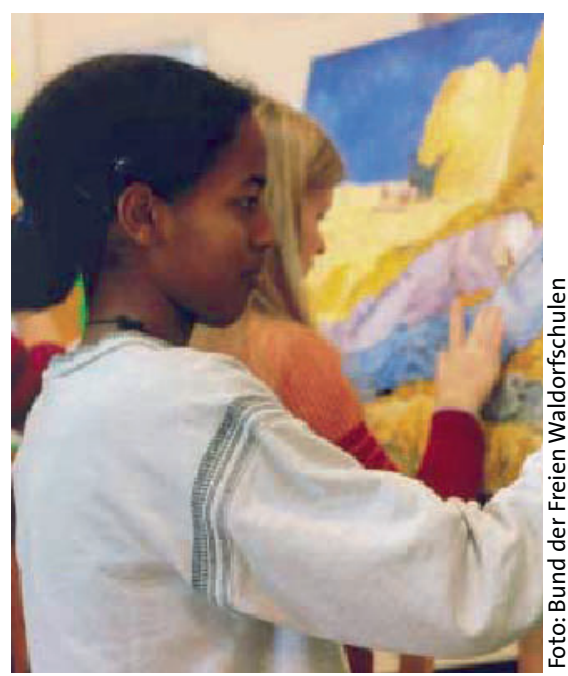

Die Allergieprävalenz bei Waldorfschülern ist niedriger als der Durchschnitt. krankungen. Dennoch: Waldorfkinder erkrankten vergleichsweise seltener.

Antibiotika im ersten Lebensjahr waren verbunden mit einem erhöhten Risiko für Asthma (OR 2,79), Rhinokonjunktivitis $(1,97)$ und atopisches Ekzem $(1,63)$. Auch die frühe Gabe von Antipyretika ging einher mit einem höheren Risiko für Asthma $(1,54)$ und atopisches Ekzem $(1,32)$. Kinder, die gegen Masern, Mumps und Röteln geimpft waren, litten häufiger an Heuschnupfen. Hingegen entwickelten Kinder, die eine Masernerkrankung durchgemacht hatten, seltener IgE-vermittelte Allergien $(0,64)$. Die Risikoerhöhung nach früher Antibiotikagabe erklärt sich möglicherweise durch die zentrale Rolle der intestinalen Mikroflora bei der Reifung des Immunsystems.

Fazit: Diese multinationale Querschnittsstudie bestätigt, dass Waldorfschulkinder seltener Allergien entwickeln als andere Kinder aus derselben Region. Welche der damit assoziierten Faktoren eine kausale Rolle spielen, ist zu diskutieren. cjh

Flöistrup $\mathrm{H}$ et al. Allergic disease and sensitization in Steiner school children. J Allergy Clin Immunol 2006; 117: 59-66

\title{
Allergieprävention 2: Virusinfektionen
}

\section{Gemäß der Hygienehypothese schützen exogenene Stimuli während der frühen Kindheit vor allergischen Erkrankungen im späteren Leben. Eine schwedische Arbeitsgruppe versuchte speziell der Rolle von viralen Infektionen in diesem Zusammenhang auf die Spur zu kommen.}

\footnotetext{
Corscher des Stockholmer Karolinska-Instituts untersuchten 246 Kindern vom Zeitpunkt ihrer Geburt bis zum Alter von zwei Jahren alle sechs Monate klinisch und führten Pricktests durch. Außerdem wurde spezifisches IgE gegen inhalative Allergene und Nahrungsmittelallergene gemessen. Zusätzlich wurden Serokonversionen gegen 13 der häufigsten Virusarten erfasst, darunter waren Zytomegalievirus (CMV), Epstein-Barr-Virus (EBV), Varizella-Zos-
}

ter-Virus, Adenoviren, Respiratory Syncytial Virus und Influenzavirus.

Nach 24 Monaten waren bei insgesamt 59 Kindern (24\%) Sensibilisierungen nachweisbar, meist gegen Milch, Hühnereiweiß und Erdnüsse. Kinder mit einem positiven Antikörper-Nachweis gegen nur wenige Viren zeigten tendenziell, aber nicht signifikant häufiger Sensibilisierungen gegen Allergene im Vergleich zu Kindern mit einer Serokonversion gegen zahlreiche Viren. Sig- nifikant war allerdings eine Seropositivät gegen EBV mit einer niedrigeren Sensibilisierungsrate assoziiert (Odds Ratio [OR] 0,37, um andere Einflussfaktoren bereinigt 0,34). Kinder, die gegen EBV und zusätzlich gegen CMV Antikörper gebildet hatten, zeigten ein noch niedrigeres Sensibilisierungsrisiko (OR 0,07, bereinigt 0,10 ).

Fazit: Kinder, die bis zu einem Alter von zwei Jahren eine EBV-Infektion durchgemacht hatten, zeigten in dieser Studie ein signifikant vermindertes Risiko, Sensibilisierungen zu entwickeln. Dieser Effekt war noch deutlicher, wenn die Kinder gleichzeitig seropositiv für CMV waren.

Nilsson C et al. Does early EBV infection protect against IgE sensitization? J Allergy Clin Immunol 2005; 116: 438-44 